\title{
A leadership competency model of science and technology parks: the case of Chungbuk Techno Park in Korea
}

\author{
Kyoung-Joo, Lee ${ }^{*}$, Eun-Young, Kim²
}

\begin{abstract}
Given their significant regional economic benefits, science and technology parks (STPs) have attracted continuous academic attention. To understand the predictors of performance of STPs, this study focuses on the critical impacts of leaders and develops a leadership competency model specialized for public STP leaders. The competency model identifies the qualities and conditions of an effective leader of public STPs, emphasizing management skills, bottom-up approach, and boundary spanning skills. To provide empirical support, this study adopts the case study approach and performs a behavior event interview with one of the most successful leaders of public STPs in Korea.
\end{abstract}

Keywords: leadership; competency model; boundary spanning; incubator

Submitted: July $5^{\text {th }}, 2018$ / Approved: November $22^{\text {nd }}, 2018$

\section{Introduction}

Because the formation of new technology-based firms is a critical driver of economic growth, governments in many industrialized economies have actively engaged in developing science and technology parks (STPs) to assist in the growth of firms and the regional economy. Recognizing their significant potential, researchers have paid continuous attention to the functions and operations of STPs. The most frequent goals of existing studies have been to understand the effects of STPs on the performance of venture firms (Yang, Motohashi, \& Chen, 2009; Fukugawa, 2006; Westhead \& Batstone, 1998; Westhead, 1997), the formation of innovation networks between industry and university in the parks (Link \& Scott, 2003; Vedovello, 1997), and the contributions to regional and national economic growth (Hu, 2007; Sternberg, 2004). Despite the diverse research approaches, the critical research question that has yet to be sufficiently explored is what distinguishes successful STPs from the less successful ones and what are the critical factors that explain the variable performance of STP organizations. Despite increasing policy concerns over how to measure the performance of a STP (Albahari, Catalano, \& Landoni, 2013; Bigliardi, Dormio, Nosella, \& G. Petroni, 2006), few studies have made notable contributions to identifying their critical performance factors and empirically examining their effects.

With the goal of addressing the limitations of the existing literature, this study considers the leaders of STPs as critical to explaining their organizational performance and focuses on examining the qualities and conditions of successful STP leaders. In any organization, effective leadership has a significant effect on performance because it provides a sense of direction and vision in accordance with environmental changes, facilitates organizational cohesiveness, personal development, and high employee satisfaction, and implements a healthy mechanism to promote innovation and creativity (Thach \& Thompson, 2006; Hollenbeck et al., 2006; Carmeli \& Tishler, 2006; Hannon, 2005; Wart, 2003). Effective leaders are a critical resource for organizational success because they significantly influence strategic decisions and their implementation (Carmeli \& Tishler, 2006). Thus, an urgent issue in an STP study is to identify the critical qualities and competences of leaders in explaining organizational performance and long-term success.

By focusing on the qualities of successful STP leaders, this study proposes a competence model tailored for public STP organizations. A competency is a measurable human capability that affects the performance of a certain job, and a competency model is the set of knowledge, skills, and personal characteristics required to achieve high performance in a job (Campion, Fink, Ruggeberg, Carr, Phillips, \& Odman. 2011; Hollenbeck et al., 2006; Marrelli et al., 2005; Lucia \& Lepsinger, 1999; McClelland, 1998; McClelland, 1973). Since the seminal study of McClelland (1973), competency modeling has expanded broadly into a variety of fields and disciplines, including leaders' competency for creativity and innovation (Halbesleben, Novicevic, Harvey, \& Buckley 2003), project managers (Müller \& Turner, 2010), the hospitality sector (Testa \& Sipe, 2012), health care professionals (Marrelli et al., 2005), medical education (Talbot, 2004), and even a specific firm, such as $3 \mathrm{M}$ (Alldredge \& Nilan, 2000). In particular, as a competency model specialized for organizational leaders, leadership competency modeling identifies the specific competencies required to enhance leadership effectiveness (Thach \& Thompson, 2007; Hollenbeck, McCall, \& Silzer 2006; Hood \& Lodge, 2004; Halbesleben et al., 2003). By proposing a map of the core qualities of effective leaders, a leadership competency model can guide the critical HRM process of selecting, evaluating, and training and developing leaders.

This study makes an attempt to construct a leadership competency model tailored for STPs by focusing on the management skills, bottom-up approach, and boundary spanning skills. Public STPs, funded by regional or national governments, play a crucial role in providing business support to new technology-based firms and nurturing regional and national economic growth. STP leaders can have

(1) College of Social Science, Gachon University, 1342 Seongnamdaero, Sujeong-gu, Seongnam-City, Gyeonggi-do, Republic of Korea.

(2) Pohang Technopark, 601, Jigok-dong, Nam-gu, Pohang-si, Gyeongsangbuk-do, Republic of Korea

${ }^{*}$ Corresponding author: leekjoo@gachon.ac.kr 
detrimental effects on operational performance because they are in charge of formulating long-term organizational visions and strategies, designing effective organizational structures, implanting systemic human resource management (HRM), and forming extensive external networks with critical stakeholders.

\section{STP Leadership Competency Model}

\section{Management Skills}

Management skills comprise a significant part of the leadership competency of STPs because many public organizations suffer from problems associated with formal bureaucracies (Walker et al., 2011; Denhardt \& Denhardt, 2000). With respect to the operation of public organizations, a longstanding critique has been bureaucratic inefficiency caused by waste, delay, and unresponsiveness in organizational operations. The management skills of public STPs represent the ability to efficiently use the organization's resources and to make effective decisions regarding planning, organizing, staffing, and controlling incubator operations to achieve higher performance (Carmeli \& Tishler, 2006; Hannon, 2005; Lalkaka, 1996). Management skills of leaders in public STPs indicate the organization's clear strategic vision and its valid plans to achieve its goals. The leader's managerial skills include a variety of abilities, such as persuasiveness, administrative ability, knowledge about group skills, and social skills (Carmeli \& Tishler, 2006), which have strong implications for organizational performance.

The role of the STP leader is to organize and direct all of an organization's activities by making strategic and operation decisions that are highly significant to its performance and success. The essential planning issue that an effective leader of STPs should address is to select a sub-sectorial niche on which organizational efforts should focus (Lalkaka, 1996). Furthermore, management skills enable STP leaders to design efficient work structures and enable organizations to make the best of precious resources while preventing irresponsible waste in public spending. The organizing capability of the leader resides in the effective structuring of resources and activities to provide counseling services, mobilize funding opportunities, and facilitate external networking to nurture the growth of venture firms. The HRM capability of the STP leader is to secure competent personnel, design systemic compensation and evaluation schemes that provide quality services and support to tenants, and enhance organizational commitment. Finally, controlling an effective leader includes designing valid performance measurements to evaluate the quality of incubating services and the efficiency of personnel, and to correct deviations from the operational standards to assure STP performance.

\section{Bottom-up approach}

In the studies of policy making and implementation, the bottom-up approach is a strategic process that captures the policy ideas and information of the actors in the focal impact domain and collaborates with the actors in order to reflect their ideas into the higher process of making policies (Ossenbrink, 2018; Koontz \& Newig, 2014; Sabatier, 1986). Although the top-down approach of policy making starts with a policy decision made by governmental entities (Sabatier, 1986) and emphasizes a strategic intent that the policy pursues to achieve (Ossenbrink, 2018), the bottom-up approach captures the ideas from the actors and entities in the target domain of the focal policy. Rather than assuming that policy makers can directly control implementation in the lines of top-down authority, the bottom-up approach presumes that policy makers can make better decision when they understand what resources are necessary for the work performance and how the task may affect the behaviors of the policy target (Koontz \& Newig, 2014).

Taking an inductive perspective, the bottom-up approach adopts a lens for drawing a broad spectrum of policy ideas from a variety of governance levels, entities, and policy fields, moving them to the top policy-makers in both the public and private sectors (Ossenbrink, 2018; Koontz \& Newig, 2014; Sabatier, 1986). Bottom-up approach captures information provided by the actors who are in the impact domain of the policy, such as firms and individuals who are in the position of driving innovation in a particular sector (Ossenbrink, 2018). The approach uses a networking technique to identify the entities actually involved in planning, financing, and executing the relevant policy program (Sabatier, 1986). As the actors struggle in the impact domain of innovation policy, they have a vested interest in knowing the policy influences and outcomes and their interpretations of policy signal could have significant implications to the successful implementation of a focal policy (Ossenbrink, 2018). As the actors perceive problems in the field and try to develop the strategies to deal with them, they are able to evaluate the relative importance of a variety of governmental programs and policy measures in solving those problems (Sabatier, 1986).

The bottom-up approach constitutes a core competency of leaders in public STPs as it enables them to align assistance strategy with the needs of tenants. The significant aspect of bottom-up approach that the successful STP leaders should have is networking with tenants firms to gain the ideas and information to develop the assistance and supports tailored to the actual needs of the tenants firms. The effective portfolio of STP's assistance services is to devise the customized supports that could meet the real needs of individual firms while preventing the potential waste and loss in public spending (Lalkaka, 1996). Tenants' needs for managerial resources and counseling services are diverse with respect to industry sectors, technologies, and growth stages (Vanderstraeten \& Matthyssens, 2012; Rice, 2002) and the bottom-up approach could signify the value of customization in the incubating process. The bottom-up approach of STP leaders facilitates capturing the ideas and information from the tenants and help designing the effective assistance and counseling to leverage actual business growth and the development of venture firms. The irrelevant services not only prevent the optimal use of valuable resources but also raise the problems of fiscal loss and waste in public spending for which bureaucratic organizations are often criticized. Thus, the bottom-up approach of STP leaders facilitates developing highly needed business support to fortify the concrete growth of tenant firms while maximizing the accountability of public spending. 


\section{Boundary Spanning Skills}

One of the most important roles played by effective STPs is to act as an intermediary between the tenant and regional firms and external resource providers. Effective organizational leadership is actualized when an organization collaborates across boundaries to achieve goals that it has in common with others (Takanashi \& Lee; 2018; Ernst \& Chrobot-Mason, 2011). A significant aspect of high-performing leaders is the ability to form large diversified collaborations with external organizations. Boundary spanning leadership is the ability to create a common direction, alignment, and commitment across group boundaries to achieve a higher goal (Ernst \& Chrobot-Mason, 2011). Conceptualized in innovation studies, boundary spanning refers to promoting information flows across the boundaries of different organizations to accelerate the absorption, sharing, and transmission of information, thus significantly contributing to organizational performance and innovations (Lee, 2014; Lee, Ohta, \& Kakehi, 2010; Tushman \& Scanlan, 1981; Aldrich \& Herker, 1977). Boundary spanning leadership enables organizations to achieve results together that go beyond the achievements of a single organization (Ernst \& Chrobot-Mason, 2011).

The boundary spanning leadership of STPs helps expand connections and collaboration with external stakeholders who provide these parks with resources critical for survival and growth. STPs' external networks facilitate tenants' access to external resources, such as counseling and mentoring, R\&D grants, human capital, marketing and distribution, venture capital, and government grants and loans. Through mediation, STPs can increase the visibility, credibility, and understandability of tenant firms in the eyes of external investors (Bergek \& Norman, 2008). Through effective boundary spanning, an incubator leader can establish institutionalized networks that allow tenants to gain access to external resources beyond the personal social capital or connections available to a few people (Bøllingtoft \& Ulhøi, 2005). The boundary spanning capability of incubator leaders achieves higher incubating performance by providing venture firms with external networks to mobilize critical resources.

\section{Methodology}

Our empirical analysis adopts the case study of a successful leader on the basis of the behavior event interview (BEI). The BEI is a unique interview methodology highly relevant for the competency modeling process (Campion et al., 2011; Marrelli, Tondora, \& Hoge 2005; McClelland, 1998). In the BEI, top performers are interviewed individually to gain information about what they did, thought, intended, and felt in changing situations or when coping with difficult problems (Marrelli et al., 2005). It is a highly in-depth interviewing process aimed at collecting detailed information on past situations on the job and understanding the ideas and intentions behind the actions (Campion et al., 2011; McClelland, 1998). A BEI is used to identify and select relevant informants to collect empirical evidence supporting the theoretical model. Selecting STPs for the case analysis in this study proceeded through following screening processes.

First, we used open resources to collect basic demographic data on all of the formal and incumbent directors of eighteen STPs. An investigation into the directors of STPs formed a list of 79 directors who served from 1997 to 2015, which included basic information on name, age, gender, academic background, work experience, and major achievements during a four-year tenure term.

Second, we formed an initial pool of outstanding leaders in question by pursuing recommendations from the incumbent and former chairman of the Korea Techno Park Association, the trade association comprised of directors of eighteen STPs. Because the association holds regular directors' meetings and discussions to address the managerial and policy issues of STPs, the chairman is believed to provide highly relevant information regarding the directors who exercised outstanding leadership and achieved excellent performance. The inquiry provided a pool of three directors with good reputations and outstanding performance records. On the basis of the recommendation, we investigated the achievement and performance evaluations of leaders done by the Korea Institute for Advancement of Technology (KIAT). As the founder and governing agency of STPs, the KIAT performs annual assessments of STPs' management and operational performance. All three directors won the Best-Performance Prize multiple times during their terms. Furthermore, all recommended leaders were reappointed after successfully completing their first service term. In general, the tenure of an STP director is four years, and all leaders are reappointed through recognition of good performance.

Third, the final selection of the leader for the case study was based on the cooperative responses from the informant and favorable access to the research data and internal cooperation, which led to the selection of the N-Director of Chungbuk TP located in the Chungcheongbukdo Province. To engage in an in-depth analysis of the leadership competency of the N-Director, this research conducted an extensive search of the open data and visiting interviews to supplement the second-hand information. Investigation of the open data relied on a newspaper portal service provided by the Korea Press Foundation. The web service allows articles in most newspapers and magazines published in Korea to be searched, and the search generated more than 500 related articles. The news articles revealed detailed information on operational activities, service programs, external alliances, and the achievements of the leaders because the STPs actively disseminate information for public relations purposes.

Fourth, after analyzing the major events of Chungbuk TP, we conducted four structured and semi-structured interviews with not only the N-Director but also team managers (see the Appendix). The interview questions were designed to ask why and how the N-Director initiated organizational changes, adopted new programs, and formed external alliances, and what the leader thought, intended, and felt when initiating organizational changes and introducing new policies. Furthermore, to complement the focused interviews, four interviews with managers and researchers in three other STPs (Chungnam TP, Daejeon TP, and Gwangju TP) were conducted to validate the theoretical insights in different STP contexts and to infer the unexplored dimensions of the role and effect of successful STP leaders (See Appendix). 


\section{Case study of N-Director in Chungbuk Techno Park}

Chungbuk TP, which is the focus of this study, was sponsored by the Ministry of Trade, Industry and Energy (MTIE) in 2003, and it consists of two units and three centers, such as Policy Planning Unit, Incubating Unit, Next Generation Semiconductor Center, IT Convergence Center, and Bio Center. Similar to numerous other STPs, the initial phase of development focused on the construction of physical infrastructure to provide space for tenant firms and R\&D centers (KISTEP, 2012). Since 2008, the strategic focus has changed to promoting innovations in four strategic industries in the region, such as biotechnologies, semiconductors, electricity and electronics components, and next-generation batteries. The N-Director was inaugurated in October 2010 as the third director of the organization. Since taking leadership of the park, the N-Director has archived outstanding performance. With respect to external evaluations, the Chungbuk TP won the Best-Performance Prize in 2011, 2012, and 2014 in the KIAT Annual Techno Park Management Performance Evaluation. Regarding the performance of incubating activities, the number of tenant firms increased from 52 in 2008 to 88 in 2013, the number of employees in tenant firms, from 758 in 2008 to 2,941 in 2013, and the revenue of firms, from US $\$ 0.37$ billion to US $\$ 1.25$ billion during the same period.

\section{Management Skills}

After the inauguration in 2010, the N-Director took the initiative to select strategic industries that the STP would support from a longterm perspective. Simultaneously, the N-Director actively engaged in reforming the organizational structure and HRM systems to effectively foster growth in the strategic industrial sectors. To select the strategic industries, the N-Director formulated basic guidelines to review the emergence of new industries and investigated regional market needs. Furthermore, the more significant concern that the incoming director should address urgently was the organizational rigidity and low employee morale. Although the STP organization has grown consistently since its inception in 2003, it has suffered from the organizational problems prevalent in many bureaucratic, public organizations. Similar to many other public organizations in Korea, the Chungbuk TP offered strong job security as a public organization, seniority-based wages and promotion, and a strict hierarchy in the decision-making process. All of these issues caused low organizational vitality, strong sectionalism of individual units, and low employee work motivation.

The underlying guideline that the N-Director adopted to reform the public organization was fitting its organizational structure and necessary functions to the new strategic goals of the organization. In a reform effort, the $\mathrm{N}$-Director eliminated functional duplication between different organizational units and centers. Because different ministries of the central government funded the establishment of internal units and centers (Oh \& Lee, 2013), they indicated strong sectionalism and wasteful duplication of similar functions. As an illustration, large operational and functional overlaps existed between the Semiconductor Center and the Embedded Semiconductor Center and between the Traditional Pharmaceutical Center and the Healthcare Medical Center. The reform initiative integrated them into the next-generation Semiconductor Center and the Bio Center, respectively.

In addition to fitting the organizational structure to the strategies, the N-Director reformed the HRM systems, which exerted a strong influence on employee motivation and the control of work behavior. The N-Director's basic belief is to build a work environment in which managers and employees are motivated to proactively perform their work.

"Leader should consider how to build harmony among organizational members, vertically as well as horizontally, and how to lead them to achievement of strategic goals. To do this, I believe, I should create a work environment in which all the organizational members work proactively rather than passively" (Interview with N-Director, 2015). First, with the goal of vitalizing the organization, the N-Director adopted an open competition rule in which employees jockeyed for managerial positions of teams or units. The traditional seniority-based wages and promotions had restricted healthy competition among employees, which resulted into low motivation and passive work attitudes. The open competition rule aroused healthy tension among the senior employees by creating strong performance pressure. The senior employees should achieve high work performance to be promoted to a managerial position. Furthermore, they faced the continuous competitive pressure of losing the position when they failed to meet the expected performance results.

Second, the N-Director adopted the empowerment rule for junior employees in planning and granting project funds. This rule delegated full authority to outstanding junior employees to propose and plan a funding project, even if relatively small. By endowing project leadership opportunities to junior employees, the rule assisted in both motivating young employees to actively pursue funding chances and achieve high performance and creating strong competitive pressure on the unit and team managers, leading to the formation of proactive work attitudes in general.

Third, to break down the traditional sectionalism among internal units, the N-Director introduced a job rotation policy in which employees changed their jobs regularly by moving to different functional units and teams. Because the individual units and centers were funded by different agencies of the central government, they pursued independence and autonomy and exhibited strong isolation and duplication in their work operations. As a solution to the problems, the job rotation provided crucial opportunities to understand the work and roles of different units. The job rotation promoted a mutual understanding between employees of different functions and formed inter-personal and inter-unit cohesion.

Along with the aforementioned "stick" policies, the N-Director also adopted "carrot" policies to foster work motivation and employee morale. One of the most significant reforms was to increase the level of employee wages to that of central government officials. Because 
the STP represented a newly established regional organization, its wages and fringe benefits were set at much lower levels than that of the central government, which significantly demotivated employees. Through continuous petitions and negotiations with the governing agency, the N-Director increased employees' basic pay to the pay levels of public officials in the central government, strongly increasing employee morale. Furthermore, to foster organizational membership and loyalty, the N-Director actively supported the formation of employee social clubs and cultural events and provided various fringe benefits in accordance with organizational performance.

\section{Bottom-up approach}

The bottom-up approach in the operation of STP is to capturing the ideas and information from the tenant firms and individuals and reflects them to designing of the policy and strategy of business assistance services. An ultimate goal of STPs is to provide supportive services to nurture the development of innovative firms in the region's strategic industries. A distinguishing aspect of the N-Director's leadership was to capture ideas and information regarding the actual needs of venture firms. Such knowledge and insights have been reflected into the STP's policy and strategy for developing the supportive consultation programs. Furthermore, the bottom-up approach helps not only building networks with venture firms, but also identifying creative R\&D ideas that could gain governmental research funds.

One way to foster the growth of tenant firms and regional strategic industries as initiated by the N-Director is to identify venture firms' creative "seed" ideas and develop them into full-fledged R\&D projects sponsored by external funding agencies. The nurturing process starts with a regular meeting with venture firms to identify R\&D needs and creative ideas. Direct discussions with the firms often lead to identifying breakthrough ideas that have strong potential for technological innovations and new business opportunities. After developing a pool of potential ideas, the nurturing process undergoes a screening procedure in which professionals and experts in the related technological fields set the project development priority. The selected ideas were refined and modified into formal proposals to be submitted to governmental funding agencies.

Another way to facilitate the growth of venture firms is to develop incubating programs tailored to the individual needs of firms that are the ultimate beneficiary of the services. Developing supporting services started with prior investigations of tenant needs, which were reflected in the customized design of supporting programs. The $\mathrm{N}$ Director's bottom-up approach in the development of business assistance originated from the belief that, as the service needs of tenant firms have become more specific and complicated, achieving tenants' satisfaction required a more proactively designed support system. A prior study on firms' needs helps to reorient the development of support services from the point of view of tenant firms and proposes different combinations of support in accordance with the firm's growth stage and industrial differences.

As an illustration, the customization efforts of support services have led to fortifying the Contact Center, which is a specialized incubating service center based on a membership system. The characteristic aspect of the center was to combine a variety of supporting services provided by different organizations, such as governmental agencies, public R\&D institutes, and private enterprises, into a "onestop service package." The packaged services are tailored to venture firms' individual needs, and the specific services include supporting the formulation of business strategies, identifying proper public funding agencies, writing funding proposals, and accessing external supporters. As the first component of the packaged program, technology consulting diagnoses problems at every stage of corporate growth and sends experts from various technological fields who can provide appropriate solutions to the identified problems. Without the customized program, a frequently raised problem is that incubatee firms should pursue different services from individual agencies, thus utilizing substantial time and effort in gaining less helpful support.

\section{Boundary Spanning Skills}

Some of the most significant resource providers of STPs in Korea are the ministries and agencies of the central government; in particular, a large R\&D fund typically comes from the central government (Oh \& Lee, 2013). Thus, the N-Director's extensive networking with funding ministries has enabled the Chungbuk TP to achieve two-way communications, both top-down and bottom-up, and to coordinate the policy directions of key stakeholders, such as the central government, the regional governments, and local industries. On the one hand, extensive networks with public officials in ministries offer access to critical information on the basic direction and goals of R\&D funding policies adopted by individual ministries. To receive large grants, STPs' proposals should be developed in line with the basic directions of policy programs.

"If we can get some tips from the central government, we can write the proposal in accordance with the goals and direction of the funding agency. It increases the possibility of granting a large fund. It is like a rush into battleground. I directly visit the key persons who know the real goals of research funding programs and expand communication with them" (Interview with N-Director, 2015).

On the other hand, leaders' close networks with funding ministries are critical channels through which the STP could appeal to funding agencies regarding its regional needs. Thus, a critical role of the N-Director is to effectively deliver the needs and ideas of local industries. Because government funds in Korea have strict regulations regarding where and how they are spent, failing to reflect the local needs in the funding plan could result in an ill-designed and less useful grant.

"We have deeper knowledge about local characteristics and specificneeds in this region than central government as we make the regional promotion plans and implement them. To bring funds tailored for local situations, I need to meet them again and again. I have to prepare the well-made story lines to justify why some types of aid are needed especially for this region" (Interview with the N-Director, 2015).

In addition to the central government, the critical role of STP leaders is to develop close collaborations with public research institutes, 
regional universities, and business enterprises in strategic industry sectors to form a regional innovation cluster. On the basis of the belief that close connections between public and private institutions can promote technology transfers, the N-Director has actively engaged in building alliances that help tenant and regional firms gain access to external technologies and resources. The N-Director offered collaboration plans to strategic firms by continuously touting the benefits of establishing business entities in the regional cluster, including support of public $R \& D$ institutes and subsidies from the regional government.

"We should endlessly send out signal that you can make money here. We know what business the company is engaged in, who is the key person, and how to entice them to move into this region. I know how to give them necessary carrots to bring it in" (Interview with the $\mathrm{N}$ Director, 2015).

One of the most representative networking programs that the $\mathrm{N}$ Director organized was the "Global Commercialization Networking Program for the Pharmaceuticals-Bio in Chungchung Areas," which was a university-industry-government (UIG) consortium sponsored by the Ministry of Knowledge and Economy (currently, the Ministry of Science, ICT, and Future Planning) in 2011. With the goal of constructing a regional innovation cluster in the pharmaceutical and biotech industry, the Chungbuk TP took the initiative of organizing the UIG consortium and attracted total investments of US\$144.4 million from the public and private sectors. By playing a catalytic role in forming collaborative innovation networks in the region, the UIG consortium enticed a variety of innovation entities, such as universities, governmental research institutes, large established firms, and small venture firms.

A notable aspect of the consortium was the establishment of a contract manufacturing organization (CMO) by LG Life Sciences, one of the largest producers and $\mathrm{R} \& \mathrm{D}$ investors in Korea. In the pharmaceutical industry, the CMO is a specialized service provider that offers outsourcing services to client firms in the long value chain of activities, from drug development through manufacturing to distribution. Because of the inherent complexity and enormous costs of $\mathrm{R} \& \mathrm{D}$ and commercial production related to drugs, many pharmaceutical firms are highly specialized in certain value-chain activities, and outsourcing to a CMO helps firms save substantial upfront capital investments for drug development. By implementing a critical infrastructure for developing a pharmaceutical innovation cluster, LG Life Sciences' CMO service could assist in forming new venture firms specialized in R\&D and in accelerating the commercialization of their research achievements.

\section{Discussion and Conclusion}

Given the significant economic contributions that successful STPs can make at both the regional and national levels, this study pursued the elucidation of the critical factors that predict the diverging performance results of STPs. To fill the void in the existing STP literature, this study focused on leadership competency as a critical factor of STP performance. By examining the critical qualities and conditions of successful STP leaders, it proposed a competence model tailored for STP leaders and provided empirical support to the model on the basis of an in-depth case study of the N-Director of Chungbuk TP in Korea. The leadership competency model in this study suggested the following competences as essential qualities of successful of STP leaders.

First, management skills of STP leaders help design and implement effective management systems that formulate the strategic planning of STP activities, construct effective organizational structures to carry out the plans, and motivate employees to achieve organizational objectives. A core aspect of the management skills of public STP leaders is to align the organizational structure with the strategic direction. Leaders' managerial competency establishes effective rules that guide and govern the organization's operations and activities in such a way that the strategic objectives are achieved. In particular, the case analysis of this study suggests that management skills are highly relevant to a public organization because such skills can minimize the operational inefficiencies and organizational rigidities from which bureaucratic public organizations often suffer. A chronic concern is that public organizations are plagued with bureaucratic rules, organizational rigidities, and excessive controls. The research results indicate that the critical part of HRM in public STPs is infusing healthy tension and competition among employees who tend to lose their enthusiasm for work under strong job security and excessive bureaucratic control.

Second, the bottom-up approach constitutes the key competency of successful STP leaders because it enables STPs to develop supportive services tailored to meet the actual needs of tenant firms. According to the case study, the bottom-up approach of an effective leader manifests itself in the differentiation and specialization of support services which reflects the ideas and information collected from the tenant firms and the assistance services are tailored in accordance with the growth stages and industrial differences of venture firms. By adopting a tenant's point of view, the tailored support services enhances the usability of STP services for the recipient firms, which not only enhances the effectiveness of the incubator activities but also guarantees higher accountability of public expenditures. The bottom-up approach enables STP leaders to identify highly prospective ideas of venture firms and nurture them to grow into full-fledged projects sponsored by government funding agencies. The bottom-up approach can enhance the commercial results of innovative ideas because it allows for proactive incubation support of innovative technological potential.

Third, the boundary spanning skills of STP leaders facilitate building extensive external networks through which venture firms gain access to critical resources. As a key competence of the organizational leader, boundary spanning skills enable STPs to foster cooperation with external resource providers. They help bridge different goals and interests when identifying common benefits that organizations can collectively pursue. The case analysis of this study shows that the boundary spanning activities of STP leaders involve not only identifying key information regarding the goals and directions of the government but also foster communication with government agencies to ensure that they reflect region-specific needs through the policy-making process. 
The boundary spanning skills of a leader facilitate communication with external stakeholders, coordinate strategic directions with them, and draw on common interests. These skills provide venture firms with critical external networks that enhance the accessibility to external support. Furthermore, the seamlessly organized external networks of STPs facilitate designing integrative services to effectively meet the specific needs of venture firms.

The critical benefits of leadership competency modeling is to provide HRM practitioners with ultimate guidelines for recruiting, screening, training, assessing, and rewarding critical human resources. Although STPs have different leader selection rules and processes, the competency model proposed in this study serves as the basic criteria for clarifying the essential leadership qualities required for leaders to achieve high organizational performance. Despite critical leaders' effects on the STP organization, few studies have suggested the necessary conditions for the specialized education and performance assessment of STP leaders. The research results of this study help policy makers propose effective educational programs and systemic appraisals tailored to public STP leaders. In turn, for potential STP leaders, the competency model informs them of the necessary skills, knowledge, and attitudes that public STP leaders should acquire and develop to achieve a successful career.

Although this study has made the first attempt at developing a leadership competency model specialized for public STPs, the model should be complemented by further studies to improve its theoretical validity and practical usability. First, this study focused on only a few competences out of the numerous necessary qualities and attitudes that effective STP leaders should have. A more refined approach to the competency modeling process should provide further considerations for the roles and effects of personal attitudes and characteristics. Critical individual traits, as a fundamental part of competence (Campion et al., 2011), may include self-management, proactiveness, professionalism, social skills, communication, and emotional skills because they create an essential personality basis to effectively activate the functional competences discussed in this study. Second, another critical direction of future research is to investigate interactive and correlation effects between different competences proposed in the model. The competences may complement one another, and a different set of competences can lead to higher effectiveness and better performance than others. Thus, examining interactions can assist in designing an optimal competency model that provides more effective guidance for the selection, development, and evaluation of leader competency. Third and finally, the limitation of this study is that the leadership competency model was based on the case study of a single STP leader in Korea. Thus, future research that adopts a quantitative methodology in a variety of national contexts will provide more rigorous evidence to prove the model's validity and applicability.

\section{References}

Albahari, A., Catalano, G., \& Landoni, P. (2013). Evaluation of national science park systems: a theoretical framework and its application to the Italian and Spanish systems. Technology Analysis \& Strategic Management, 25(5), 599-614. http://dx.doi.org/10.1080/09537325.2013.785508
Aldrich, H., \& Herker, D. (1977). Boundary spanning roles and organization structure. Academy of management review, 2(2), 217-230.

Alldredge, M. E., \& Nilan, K. J. (2000). 3M’s leadership competency model: An internally developed solution. Human Resource Management, 39(2, 3), 133-145. https://doi.org/10.1002/1099050X(200022/23)39:2/3\%3C133::AID-HRM4\%3E3.0.CO;2-8

Bergek, A., \& Norrman, C. (2008). Incubator best practice: A framework. Technovation, 28(1), 20-28. http://dx.doi.org/10.1016/j.technovation.2007.07.008

Bigliardi, B., Dormio, A. I., Nosella, A., \& Petroni, G. (2006). Assessing science parks' performances: directions from selected Italian case studies. Technovation, 26(4), 489-505. http://dx.doi.org/10.1016/j.technovation.2005.01.002

Bøllingtoft, A. (2012). The bottom-up business incubator: Leverage to networking and cooperation practices in a self-generated, entrepreneurial-enabled environment. Technovation, 32(5), 304-315. http:// dx.doi.org/10.1016/j.technovation.2011.11.005

Campion, M. A., Fink, A. A., Ruggeberg, B. J., Carr, L., Phillips, G. M., \& Odman, R. B. (2011). Doing competencies well: Best practices in competency modeling. Personnel Psychology, 64(1), 225-262. http:// dx.doi.org/10.1111/j.1744-6570.2010.01207.x

Carmeli, A., \& Tishler, A. (2006). The relative importance of the top management team's managerial skills. International Journal of Manpower, 27(1), 9-36. http://dx.doi.org/10.1108/01437720610652817

Denhardt, R. B., \& Denhardt, J. V. (2000). The new public service: Serving rather than steering. Public Administration Review, 60(6), 549-559. https://doi.org/10.1111/0033-3352.00117

Ernst, C., \& Chrobot-Mason, D. (2011). Flat world, hard boundaries: How to lead across them. MIT Sloan Management Review, 52(3), 1-8.

Fukugawa, N. (2006). Science parks in Japan and their value-added contributions to new technology-based firms. International Journal of Industrial Organization, 24(2), 381-400. http://dx.doi.org/10.1016/j. ijindorg.2005.07.005

Halbesleben, J. R., Novicevic, M. M., Harvey, M. G., \& Buckley, M. R. (2003). Awareness of temporal complexity in leadership of creativity and innovation: A competency-based model. The Leadership Quarterly, 14(4), 433-454. http://dx.doi.org/10.1016/S1048-9843(03)00046-8

Hannon, P. D. (2005). Incubation policy and practice: building practitioner and professional capability. Journal of Small Business and Enterprise Development, 12(1), 57-75. http://dx.doi. org/10.1108/14626000510579644

Hollenbeck, G. P., McCall, M. W., \& Silzer, R. F. (2006). Leadership competency models. The Leadership Quarterly, 17(4), 398-413. http://dx.doi.org/10.1016/j.leaqua.2006.04.003 
Hood, C., \& Lodge, M. (2004). Competency, bureaucracy, and public management reform: A comparative analysis. Governance, 17(3), 313-333. https://doi.org/10.1111/j.0952-1895.2004.00248.x

Hu, A. G. (2007). Technology parks and regional economic growth in China. Research Policy, 36(1), 76-87. http://dx.doi.org/10.1016/j. respol.2006.08.003

KISTEP (Korea Institute of S\&T Evaluation and Planning). (2012). Special Evaluation Report on Techno Park Construction Policy (in Korean). KISTEP.

Koontz, T. M., \& Newig, J. (2014). From Planning to Implementation: Top-Down and Bottom-Up Approaches for Collaborative Watershed Management. Policy Studies Journal, 42(3), 416-442. https://doi. org/10.1111/psj.12067

Lalkaka, R. (1996). Technology business incubators: critical determinants of success. Annals of the New York Academy of Sciences, 798(1), 270-290. https://doi.org/10.1111/j.1749-6632.1996.tb24870.x

Lee, K. J. (2014). Development of boundary-spanning organisations in Japanese universities for different types of university-industry collaborations: a resource dependence perspective. Asian Journal of Technology Innovation, 22(2), 204-218. http://dx.doi.org/10.1080/19761597.2014.973164

Lee, K. J., Ohta, T., \& Kakehi, K. (2010). Formal boundary spanning by industry liaison offices and the changing pattern of universityindustry cooperative research: the case of the University of Tokyo. Technology Analysis \& Strategic Management, 22(2), 189-206. http:// dx.doi.org/10.1080/09537320903498538

Link, A. N., \& Scott, J. T. (2003). US science parks: the diffusion of an innovation and its effects on the academic missions of universities. International Journal of industrial organization, 21(9), 1323-1356. http://dx.doi.org/10.1016/S0167-7187(03)00085-7

Lucia, A. D., \& Lepsinger. R. (1999). Art \& Science of Competency Models. San Francisco, CA: Jossey-Bass.

Marrelli, A. F., Tondora, J., \& Hoge, M. A. (2005). Strategies for developing competency models. Administration and Policy in Mental Health and Mental Health Services Research, 32(5-6), 533-561. https:// doi.org/10.1007/s10488-005-3264-0

McClelland, D. C. (1973). Testing for competence rather than for" intelligence. American Psychologist, 28(1), 1-14. http://dx.doi. org $/ 10.1037 / \mathrm{h} 0034092$

McClelland, D. C. (1998). Identifying competencies with behavioralevent interviews. Psychological Science, 9(5), 331-339. https://doi. org/10.1111/1467-9280.00065

Müller, R., \& Turner, R. (2010). Leadership competency profiles of successful project managers. International Journal of Project Management, 28(5), 437-448. http://dx.doi.org/10.1016/j.ijproman.2009.09.003
Oh, S. H., \& Lee. K. J. (2013). Governance System of Governmental R\&D Programs: Formation and Transformation of the Framework Act on Science and Technology in Korea. Science and Public Policy (40), 492-503. https://doi.org/10.1093/scipol/sct002

Ossenbrink, J., Finnsson, S., Bening, C. R., \& Hoffmann, V. H. (2018). Delineating policy mixes: Contrasting top-down and bottom-up approaches to the case of energy-storage policy in California. Research Policy. DOI: 10.1016/j.respol.2018.04.014

Rice, M. P. (2002). Co-production of business assistance in business incubators: an exploratory study. Journal of Business Venturing, 17(2), 163-187. http://dx.doi.org/10.1016/S0883-9026(00)00055-0

Sabatier, P. A. (1986). Top-down and bottom-up approaches to implementation research: a critical analysis and suggested synthesis. Journal of Public Policy, 6(1), 21-48. https://doi.org/10.1016/j.respol.2018.04.014

Sternberg, R. (2004). Technology centres in Germany: economic justification, effectiveness and impact on high-tech regions. International Journal of Technology Management, 28(3-6), 444-469. http://dx.doi. org/10.1504/IJTM.2004.005298

Takanashi, C., \& Lee, K. J. (2018). Boundary spanning leadership, resource mobilisation, and performance of university-industry R\&D projects: a study in a Japanese university. Technology Analysis \& Strategic Management. https://doi.org/10.1080/09537325.2018.1490397

Talbot, M. (2004). Monkey see, monkey do: a critique of the competency model in graduate medical education. Medical Education, 38(6), 587-592. https://doi.org/10.1046/j.1365-2923.2004.01794.x

Testa, M. R., \& Sipe, L. (2012). Service-leadership competencies for hospitality and tourism management. International Journal of Hospitality Management, 31(3), 648-658. http://dx.doi.org/10.1016/j. ijhm.2011.08.009

Thach, E., \& Thompson, K. J. (2007). Trading places: Examining leadership competencies between for-profit vs. public and non-profit leaders. Leadership \& Organization Development Journal, 28(4), 356375. http://dx.doi.org/10.1108/01437730710752229

Tushman, M. L., \& Scanlan, T. J. (1981). Boundary spanning individuals: Their role in information transfer and their antecedents. Academy of Management Journal, 24(2), 289-305. doi: 10.2307/255842

Vanderstraeten, J., and Matthyssens, P. (2012). Service-based differentiation strategies for business incubators: Exploring external and internal alignment. Technovation, 32(12), 656-670. https://doi. org/10.1016/j.technovation.2012.09.002

Vedovello, C. (1997). Science parks and university-industry interaction: geographical proximity between the agents as a driving force. Technovation, 17(9), 491-531. https://doi.org/10.1016/S01664972(97)00027-8 
Wart, M. V. (2003). Public-Sector leadership theory: An assessment. Public Administration Review, 63(2), 214-228. https://doi. org/10.1111/1540-6210.00281

Westhead, P. (1997). R\&D 'inputs' and 'outputs' of technology-based firms located on and off Science Parks. R\&D Management, 27(1), 4562. https://doi.org/10.1111/1467-9310.00041
Westhead, P., \& Batstone, S. (1998). Independent technology-based firms: the perceived benefits of a science park location. Urban Studies, 35(12), 2197-2219. https://doi.org/10.1080/0042098983845

Yang, C. H., Motohashi, K., \& Chen, J. R. (2009). Are new technology-based firms located on science parks really more innovative?: Evidence from Taiwan. Research Policy, 38(1), 77-85. http://dx.doi. org/10.1016/j.respol.2008.09.001 
Appendix 1. Interview Record

\begin{tabular}{llll}
\hline Date & Techno Park (TP) & Family Name and Initials & Rank and Function \\
\hline July 2015 & Chungbuk TP & J. S., Park & Manager of Management Planning Team \\
August 2015 & Chungbuk TP & J. S., Park & Manager of Management Planning Team \\
August 2015 & Chungbuk TP & S. K., Min & Manager of Management Planning Team \\
August 2015 & Chungnam TP & S. J., Yang & Manager of Policy Planning Team \\
August 2015 & Chungnam TP & N. K., Song & Researcher in Policy Planning Team \\
August 2015 & Daejeon TP & J. M., Whang & Researcher in Regional Industry Support Team \\
August 2015 & Gwangju TP & A.Y., Oh & Researcher in Regional Industry Support Team \\
November 2015 & Chungbuk TP & C. H., Nam & Director of Techno Park \\
November 2015 & Chungbuk TP & S. W., Kwon & Manager of Industry Planning Team \\
\hline
\end{tabular}

